\title{
Reproductive Health of Adolescent Girls: A Questionnaire-Based Study in Coimbatore City (Menstrual Hygiene - Matters)
}

\author{
Dr.Uma Devi T. \\ Professor, Mohamed Sathak A J College of Nursing, Chennai
}

\begin{abstract}
-
Background: Menstrual hygiene is a difficult health issue that's insufficiently acknowledged. Lack of adequate privacy and sanitation of toilets for the adolescent girls make them build susceptible to mental, emotional and physical downside particularly throughout their unwell days.
\end{abstract}

Objectives: To study the reproductive health of the adolescent girls in Coimbatore City.

Method: A descriptive, cross-sectional survey study was conducted among 810school going adolescent girls from Coimbatore city.

Results: Out of 810 respondents, It is observed from the results that $31.7 \%$ (257) of the respondents fall in the age group of 16 years (mean 15.5 years, SD 1.16); 87.9\% (712) of the respondents were living in the urban area; $84 \%$ (680) of the respondents were from nuclear family;60.4\% (489) of the respondents had normal body mass index (mean 20.39,SD 8.9); $57.2 \%$ (463) of the respondents' haemoglobin showed a normal range with the mean level of 11.98 and SD of 7.42;50.1\% (406) of the respondents were consuming fast / junk food; only a small number of the respondents involved in regular physical activities. Menstrual pattern of the respondents reveals that $50.7 \%$ of the respondents attained menarche between the ages of 13 and 14 years; 81.5\% (660) of them had regular menstruation; 70.2\% (569) of the respondents had normal menstruation i.e. for every 21- 35 days; $64.4 \%$ (522) of the respondents had menstrual bleeding between 3 and 5 days; $69.0 \%$ of the respondents have bleeding on the second day of menstrual cycle; $63.70 \%$ (516) of the respondents change 2-4 pads during menstruation. Findings from the study have identified a consistent $83.83 \%$ of the adolescent girls with significant menstrual morbidity and a highly significant association between all combinations of knowledge, belief, pain, anthropometric measurement, diet pattern, symptoms and daily life interference.

Conclusion: Adoption of prime quality menstrual hygiene can play a very important role in bar of RTI and Cancer of cervix among the women population. Thus promoting positive attitudes towards management of menstrual problems and related issues among the adolescent girls is that the need of hour.

Keywords - Menstrual Hygiene; Adolescent Girls; Knowledge and Practices

\section{Introduction}

Adolescence may be an amount of life with specific health and organic process desires and rights. All societies acknowledge that there's a distinction between being a child turning into an adult. The transition from childhood to adulthood is outlined and recognized otherwise between cultures and over the time. Within the past, it's usually been comparatively speedy in some societies. In several countries, however, this is often dynamical and therefore the amount between childhood and adulthood is growing longer with a lot of distinct.

Menstrual cycle may be a sign of health and it will be used as a strong tool within the assessment of traditional development for the exclusion of pathological conditions.
Globally, $52 \%$ of the feminine population $(26 \%$ of the entire population) is in their reproductive age. Menstruation may be a monthly challenge for billions of ladies and girls worldwide. More than 800 million girls and women between the age of 15 and 49 are menstruating on any given day. The typical woman can have concerning 450 discharge cycles over or so38 years of her life; this interprets to managing menstruation for roughly vi.25 years. Menstrual disorders are common among adolescents. By late adolescents, $75 \%$ of girls experience problems associated with menstruation (Padmavathi,2012).

\section{Significance of the Study}

Menstruation is an essence of reproduction, a window of opportunity to teach about the changes occurring in the 
body, fertility, contraception, and other aspects of sexual and reproductive health. Hence, menstrual health is fundamental to the dignity and well-being of women and girls. There are various reasons tied with the menstruation which makes the menstrual hygiene and health as an unattended health issue. Such reasons are too much attention only on physical structure, lack of menstrual hygiene management hardware, lack of menstrual hygiene management software, health risks of poor menstrual hygiene and unmet needs of menstrual health of the adolescent in India. The experiences gained opportunities and protections given to the adolescent girls by their society and culture can build a distinction between healthiness and ill-health.

In India like developing countries, pubescence can cause social and sexual obedience for the ladies and manhood for the boys. It will produce the sensation of femineity and masculinity among the community. Social discrimination shown between the ladies and boys throughout the adolescent amount particularly throughout pubescence can confirm the flexibility to realize multiple health and biological process outcomes. This gender bias will result in unequal standing between women and boys within the following problems like education, employment, decision-making power, wedding and management over replica. Above all, despite seldom being critical, menstrual abnormalities has important effects on personal and social lifetime of adolescent girls and women thereby reduces their quality of life.

Adolescent girl's and women's health matters not solely to women themselves. It's additionally crucial to the health of the youngsters they're going to bear. This underlines a very important point: paying due attention to the health of ladies and girls nowadays is associated not only for the present however, additionally for future generations also. This suggests that, addressing the underlying social and economic determinants of women's health - as well as education, that directly advantages women and is vital for the survival, growth and development of their children.

Therefore, the researcher felt the requirement and importance of the role in analyzing the reproductive health problems specially, the menstrual health problems among the adolescent girls. The researcher also believes that the result of study can create a broad understanding of the menstrual health problems, the adolescents face these days. Suggestions created on the findings of study won't solely facilitate the educationalist to introduce right kind of health education, however additionally it facilitates the policy makers to border appropriate and acceptable policy to fulfill the adolescent's felt needs of reproductive health and facilitate in making suitable strategy to impart coaching to the medical practitioners. This may influence the adolescent girls, the future women to become healthier and can prepare them to realize all the rights of person. Hence the study is undertaken with the subsequent statement.

\section{Statement of the Problem}

Reproductive health of Adolescent Girls: A Questionnaire-Based Study in Coimbatore City. The main objective of the study is to assess the reproductive health of the adolescent girls in Coimbatore City.

\section{Scope of the Study}

The present study attempts to provide an in-depth discussion on reproductive health in terms of menstrual problems encountered by the adolescent girls. It was carried out in the Government and Corporation schools of Coimbatore city. The study is confined to the adolescent girls aged between 13 and 18 years.

\section{Review of Literature}

The key features of the literature review are,

- Menstrual abnormalities were common among the adolescent age group.

- Urban girls had higher prevalence of menstrual abnormalities than the rural girls but at the same time the rural girls rely on self-help techniques to manage the menstrual problems as compared to urban girls.

- Most of the girls followed restrictions during menstrual cycle and the restrictions varied from, dietary practices, religious practices, house hold activities, daily bath, kitchen works and play activities, among that the religious restrictions were the leading one.

- Mothers were the source of restrictions to follow.

- Most of the studies have given their suggestion and opinion towards the betterment of the menstrual health among the adolescent girls such as diagnosis of reproductive disorders at the earliest for timely treatment to avoid complications, increase of the anticipatory guidance regarding normal menstruation by the health care providers to aid in the prompt diagnosis/treatment of menstrual disorders and to decrease their associated morbidities, formulation of voluntary clinical attendance to increase the healthseeking behavior among the adolescent girls and to have services to eliminate ignorance, false perceptions and unsafe practices regarding menstruation.

\section{Methodology}

Study Design - A school based descriptive survey design.

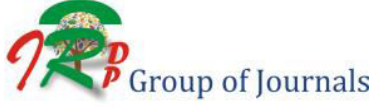


Setting - Government and Municipal Corporation schools.

Samples - Adolescent girls aged between 13 and 18 years who had attained menarche.

Tool - A self-administered pre-tested structured closeended questionnaire was used in the present study.

Sampling Process - In this study, Stratified Sampling method was adopted. There were 179 schools in Coimbatore city including primary, middle, secondary and higher secondary schools run by the government, corporation and private management. Out of this, 50 schools were managed by government and corporation. Students from different income groups such as poor, middle and upper income, different occupations such as workers, employees of private concerns, small businessmen, farmers, teachers and the like, different locations such as city, nearby villages study in government and corporation schools. So, the private schools were excluded and 50 government and corporation schools were selected at the first stage. Out of 50 schools, 30 primary and middle schools, where adolescent girls aged between 13 and 18 years won't be there. Hence they were excluded.

Hence, the remaining 30 schools which consisted of the 14 Government and 16 Corporation schools were selected finally. A request letter seeking permission was sent to the school authorities and four government schools and two schools run by Municipal Corporation gave permission to conduct the study. There were a total of 8134 girl students aged between 13 and 18 years in the six schools, which constituted the population of the study.

Qualified students met the addition criterion (teenager girls between the age of 13 to 18 years, who had attained menarche) dispersed over the simple random sampling technique using Table of Random Numbers, where each list was itemized. Using equal allocation method it is decided to take $10 \%$ of samples from each school. Finally, eight hundred and fourteen adolescent girls were selected for the research study. Care had been taken to include all the classes in the selected six schools. During the data processing, four incomplete questionnaires were found and were not included for the study.

Hence, the sample size becomes 810.Based on the comprehensive literature review related to the objectives of the research study, the study variables were identified. The questionnaire was designed by the researcher for the collection of primary data.

The questionnaire was translated into the regional language, Tamil. Before the start of data collection, the questionnaire was pre-tested with randomly selected 30 students.

\section{Findings of the Study}

Fig.1: Socio Demographic profile of Adolescent Girls

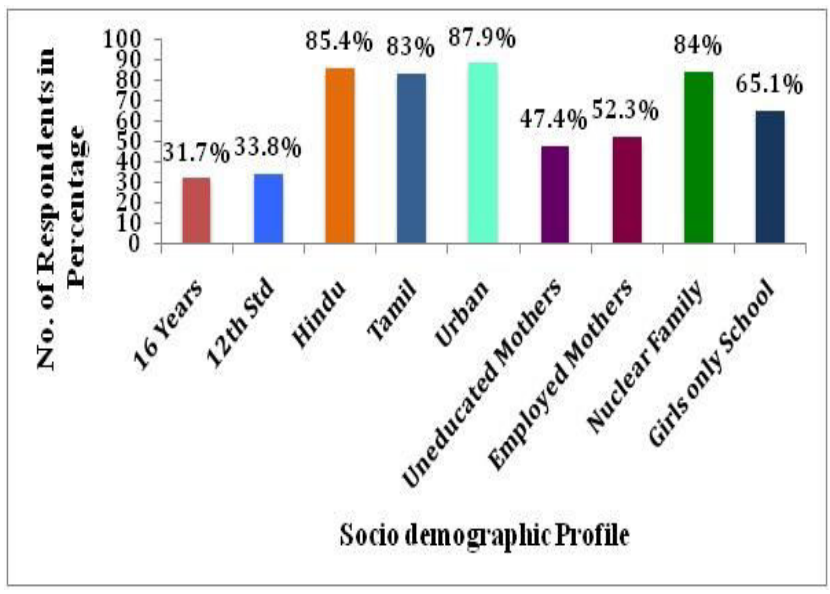

Table 1: Anthropometric details of the respondents

\begin{tabular}{|l|l|l|}
\hline \multicolumn{1}{|c|}{ Normal Characters } & \multicolumn{1}{c|}{ Frequency } & \multicolumn{1}{c|}{ Mean } \\
\hline Height $(146-165 \mathrm{~cm})$ & $85.4 \%$ & $154.1 \mathrm{~cm}$ \\
\hline Weight $(46-65 \mathrm{~kg})$ & $50.6 \%$ & $47.88 \mathrm{~kg}$ \\
\hline Body Mass Index $(18.5-24.9)$ & $60.4 \%$ & 20.39 \\
\hline Hemoglobin $(12 \mathrm{gms} / \mathrm{dl})$ & $57.2 \%$ & 11.98 \\
\hline
\end{tabular}

Nearly half $(51.8 \%)$ of the respondents involved in regular physical activities such as walking $(21 \%)$, games and sport $(9.8 \%)$ and exercises $(21 \%)$.

Fig. 2: Dietary pattern of the respondents

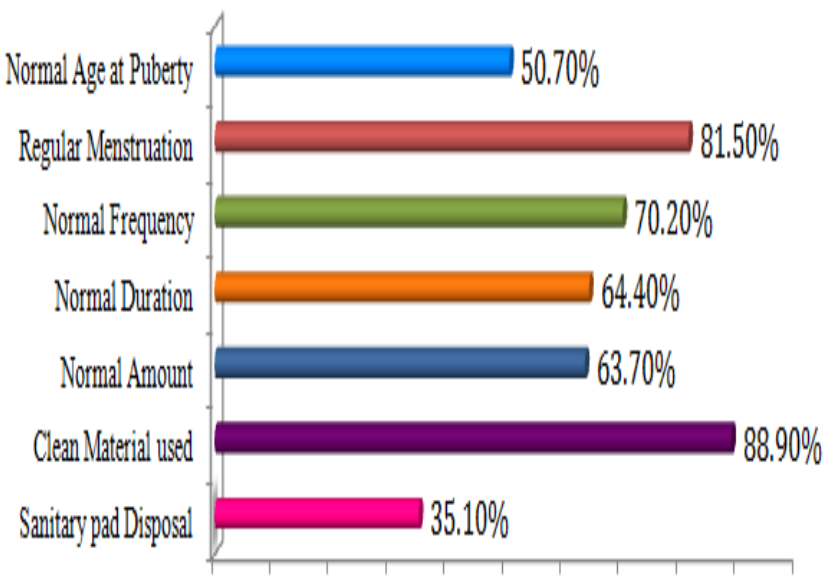

$0.00 \%$ 10.00\% 20.00\% 30.00\% 400.00\% 50,00\% 60.00\% 70.00\% 80.00\% 90,00\% 100.00\%

No. of respondents in Percentage

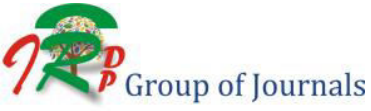


The study also reveals that $\%$ of the respondents experienced Dysmenorrhea, 20.7\% experienced blood clots and $74.59 \%$ taking rest during menstruation.

Table 2: Menstrual pattern of the respondents

\begin{tabular}{|l|l|l|l|}
\hline \multirow{2}{*}{$\begin{array}{c}\text { Menstrual } \\
\text { characters }\end{array}$} & \multicolumn{1}{|c|}{$\begin{array}{c}\text { Normal } \\
\text { pattern } \\
\mathbf{( 1 6 . 1 7 \% )}\end{array}$} & \multicolumn{2}{|c|}{$\begin{array}{c}\text { Abnormal pattern } \\
\text { (83.83\%) }\end{array}$} \\
\hline Regularity & Regular & $\begin{array}{l}\text { Irregular } \\
\text { menstruation }\end{array}$ & $22.09 \%$ \\
\hline Frequency & $21-35$ days & $\begin{array}{l}\text { Oligomenorrhea } \\
\text { Infrequent, } \\
\text { irregularly timed } \\
\text { episodes, more } \\
\text { than 35 days) }\end{array}$ & $11.04 \%$ \\
\cline { 2 - 4 } & $\begin{array}{l}\text { Polymenorrhea } \\
\text { (Frequent, } \\
\text { regularly timed } \\
\text { episodes, less } \\
\text { than 21 days) }\end{array}$ & $24.44 \%$ \\
\hline \multirow{2}{*}{ Duration } & $3-5$ days & $\begin{array}{l}\text { Menorrhagia } \\
\text { (Regularly timed, } \\
\text { more than 5 days }\end{array}$ & $20.62 \%$ \\
\hline \multirow{2}{*}{ Amount } & $\begin{array}{l}\text { 2-4 pads/day } \\
\text { (80ml/cycle) }\end{array}$ & $\begin{array}{l}\text { Hypomenorrhea } \\
\text { (Regularly timed, } \\
\text { less than } \\
\text { 2pads/day) }\end{array}$ & $21.81 \%$ \\
\hline
\end{tabular}

Analysis of the respondents shows that $56.7 \%$ of the respondents do not have earlier knowledge and friends were the source of information on menstruation (Mean=2.91). 51.6\% of the respondents had adequate knowledge on normal age at puberty, $5.8 \%$ on normal frequency of menstruation, $69.8 \%$ on normal duration of menstruation, $12.7 \%$ on the origin of menstrual bleed, $15.9 \%$ on number of pads changed during menstruation, $60.1 \%$ had adequate knowledge on the effect of menstruation on health, $67.6 \%$ had knowledge on the material to be used during menstruation and $64.2 \%$ on the method of disposal of the materials used during menstruation such as sanitary pads.

Belief about Menstruation among Respondents shows that $88.02 \%$ of the respondents believes that menstruation is a normal process, $13.95 \%$ believes that menstruation causes emotional fatigue, $86.05 \%$ believes that menstruation causes physical fatigue, $97.65 \%$ believes that menstruation affects the daily life, $85.19 \%$ believes that physical stress causes menstrual disturbances and $14.81 \%$ of the respondents believe that emotional stress causes menstrual disturbances.
Table 3: Association between Knowledge and Belief and Demographic Variables

\begin{tabular}{|l|l|l|}
\hline $\begin{array}{c}\text { Socio } \\
\text { demograp } \\
\text { hic } \\
\text { variables }\end{array}$ & \multicolumn{1}{|c|}{ Knowledge } & \multicolumn{1}{c|}{ Belief } \\
\hline Age & $\begin{array}{l}\text { Age at puberty, } \\
\text { Frequency of } \\
\text { menstruation, Duration of } \\
\text { menstruation, Origin of } \\
\text { menstrual blood, No. of } \\
\text { Pads used, Material to be } \\
\text { used, Factors affecting } \\
\text { menstruation }\end{array}$ & $\begin{array}{l}\text { Influence of } \\
\text { emonstruation on Impact } \\
\text { of menstruation } \\
\text { on daily life }\end{array}$ \\
\hline Class & $\begin{array}{l}\text { Age at puberty, } \\
\text { Frequency of } \\
\text { menstruation, Duration of } \\
\text { menstruation, Origin of } \\
\text { menstrual blood, No. of } \\
\text { Pads used, Material to be } \\
\text { used }\end{array}$ & $\begin{array}{l}\text { Influence of } \\
\text { menstruation on } \\
\text { physical health, } \\
\text { Impact of } \\
\text { menstruation on } \\
\text { daily life }\end{array}$ \\
\hline Religion & $\begin{array}{l}\text { Age at puberty, No. of } \\
\text { Pads used, Material to be } \\
\text { used }\end{array}$ & $\begin{array}{l}\text { Nature of } \\
\text { menstruation }\end{array}$ \\
\hline Tongue & $\begin{array}{l}\text { Duration of menstruation, } \\
\text { Material to be used }\end{array}$ & \\
\hline
\end{tabular}

Table 4: Association between anthropometric details, Dietary characters and Physical activities with menstrual characteristics

\begin{tabular}{|l|l|}
\hline $\begin{array}{c}\text { Anthropometric, Dietary } \\
\text { and Physical activity } \\
\text { Profile }\end{array}$ & \multicolumn{1}{|c|}{ Menstrual Characteristics } \\
\hline \multirow{4}{*}{ Body Mass Index } & Menstrual Pattern \\
\cline { 2 - 2 } Consumption of Junk Food & Frequency of Menstruation \\
\hline \multirow{4}{*}{ Skipping of Breakfast } & Frequency of Menstruation \\
\cline { 2 - 2 } & Auration of Menstruation \\
\hline \multirow{4}{*}{ Involvement in Games } & Frequency of Menstruation \\
\cline { 2 - 2 } & Duration of Menstruation \\
\hline & Menstrual Pattern \\
\cline { 2 - 2 } & Frequency of Menstruation \\
\cline { 2 - 2 } & Duration of Menstruation \\
\cline { 2 - 2 } & Amount of Menstruation \\
\hline
\end{tabular}


Analysis on the impact of menstruation on health reveals that Muscle stiffness, head ache, cramps, backache, fatigue, weight gain and general aches and pains were noticed by majority of the respondents. Forgetfulness, lower motor performance, confusion and insomnia were observed by majority of the respondents. From the behavioural component, Poor academic performance and frequent naps were experienced by majority of the respondents.

Analysis of the impact of menstruation on daily life shows that, $99.1 \%$ of the respondents were influenced in maintaining personal hygiene, $87.8 \%$ of the respondents were affected in involvement in sports, $84.1 \%$ were not involved in travelling, $84.2 \%$ of the respondents and $82.7 \%$ of the respondents are not attending social events.

\section{Suggestions}

Suggestions made out of discussions made with the respondents were,

- Increase Awareness - by Menstrual hygiene management classes

- Peer Education - to provide non-embarrassing and non-threatening setting

- Support Mechanism for Teachers- by giving training in skill based education and policy frame works

- Parent - Teacher Meet- to enhance interactive sessions

- Use of Media- to implement educational intervention programs

- Set up of Health Clinics - to supportive school environment

- Encourage Hygienic Practices - by giving importance on WASH

- Create Supportive Environment - by providing hygiene materials
- Government Support - in curriculum planning, strengthening the capacity of the teachers and to plan long term sustainable programs

- Partnership with Non-Governmental Organization

\section{Conclusion}

Right to life is one in all the elemental rights and health is one in all the important indicators reflective the standard of human life. The health of the adolescent woman impacts the health status of the population in numerous stages. Pubescence and menstrual health and it's abnormalities measure a chance to assist adolescents to grasp human development and to start building skills for making a healthy life and healthy future.

It is worthy to say that poor menstrual hygiene comes within the means of achieving the many Millennium Development Goals like MDG 3,5,7 and 8.

\section{References}

[1] Padmavathi, P., Raja Sankar.,\&Kokilavani, N. (2012). A Study to Assess the Effectiveness of Ginger Powder on Dysmenorrhoea among Adolescents in a Selected School at Erode. Asian Journal of Nursing Education Research. 2(2), April-June, 79-82.

[2] WHO updates fact sheet, (2016). Adolescents: health risks and solutions. 13 May.

[3] Basavanthappa. B.T. (2008). Community Health Nursing. Second Edition, Jaypee Brothers Medical Publishers (P) Ltd. India. 359.

[4] Dutta, D.C. (2006). Text Book of Gynaecology including Contraception. New Central Book Agency (P) Ltd, Calcutta, India, 175-177.

[5] Kothari CR., (2004) "Research Methodology" Second Revised Edition, New Age Internation (P) Limited Publishers, New Delhi.

[6] http://www.censusindia,.gov.in/2011census/C-series/C-13.html 